\title{
UN HORIZONTE AMARILLO EN LOS OJOS
}

\section{Gracia Morales}

wWw.remiendoteatro.com 

Estrenada por Remiendo Teatro el 28 de mayo de 2004 Teatro Municipal del Zaidín, Granada (un proyecto en colaboración con la Junta de Andalucía)

Dirección: Antonio H. Centeno

Intérprete: Carlos Gil Company

Ayudante de dirección: Gracia Morales

Imágenes: John Dickie

Música original: Mar Barea y Jaime Serradilla

Espacio escénico: Mariona Julbe

Diseño iluminación: Fernando Martínez Vidal

Dirección artística: Juan Antonio Valverde

Técnico de iluminación: Fernando Martínez Vidal

Técnica de vestuario: Araceli Morales

Diseño gráfico: Ángel Collado

Diseño web: Dulce Pueyos

DVD: Q73 (Natalia Moris y Juan Carlos Junquera)

Técnicos en gira: Fernando Martínez y Ramonetti

Producción: Carlos Gil Company 

(Entra un hombre, de unos cuarenta y tantos o cincuenta año. Viene arrastrando un carro en donde hay varios objetos: entre ellos, algunos sacos llenos, cerrados, y otros vacíos. Su vestimenta está gastada

y algo sucia. Amarrada a la cintura lleva una cuerda, donde hay atada una flauta, hecha a mano. Habla con alguien a quien no vemos en ningún momento: es «el muchacho».)

-Venga.

- Hay que aprovechar estos últimos rayos de sol.

-De aquí a un rato llegará la noche...

-Y la noche no sirve para andar de pie, sino para que cada uno se deje caer sobre su tierra.

— ¡Venga! Se nota que tienes poca experiencia.

— ¿Hace cuánto que naciste?

-Muy joven... No deberías andar solo tan pronto.

-Claro, ya sé. Tú no necesitas que nadie te ayude.

—Eso dices, pero yo creo que sí, que vas medio perdido...

—iAquí! ¿Qué te parece?

-Éste es un buen sitio.

—El río queda cerca, ¿lo oyes? 
—Es bueno dormirse escuchando un río,

—Rrruuuuhmmm, espanta las pesadillas...

-Y por la mañana, si hay tiempo, darse un buen baño y quitarse todo el camino de encima.

-Esos árboles nos resguardarán del viento, porque ésta es zona de viento, eso lo sabe todo el mundo. cuidas...

-Un viento que se levanta de las piedras y puede volverte loco si te des-

—Yo me quedo en este lado.

— ¡No, ahí no!

— ¡Te he dicho que ahí no!, estás muy cerca.

—Un poco más lejos.

— ¡Más lejos!

-Ahí está bien, donde no te huela...

-Por las noches, no me gusta el olor de los hombres...

(Empieza a descargar los sacos del carro. Baja tres sacos llenos.)

- No sería capaz de quedarme dormido con tu olor tapándome la cara.

—Un buen sitio, sí, señor.

— Lo raro es que no haya nadie más.

—Sólo tú y yo...

— ¿Viste a alguien? Antes de encontrarme a mí, quiero decir, ¿te cruzaste con alguien?

-Es extraño...

-Pero bueno, esas cosas pasan.

-A veces se tira uno varios días sin ver un alma.

(Empieza a extender los sacos vacíos, como si preparara un suelo. Se detiene y mira al muchacho.)

— ¿No traes nada? 
- Si quieres te presto algunos sacos, yo tengo varios...

-Para eso, hombre, para ponerlos debajo.

—Bueno, allá tú. Por la mañana tendrás que levantarte muy temprano. Así se tarda mucho en recogerla toda...

-Y, lo que es peor, siempre se desperdicia una poca...

—Eso pensé cuando te vi, ¿sabes?, a este chico le falta mucho por aprender, eso mismo pensé. Porque esta es tu primera noche solo, ¿verdad?

-Vale, no hace falta que me respondas, no hace ninguna falta.

(Cuando ya ha extendido todos los sacos, derrama los tres que están llenos sobre la superficie de los otros, con cuidado, pero también con la maestría de quien repite un gesto cotidiano. Los sacos están llenos de tierra.)

-De todas formas, tus manitas de niño te delatan. No hay más que verlas.

-Ya las tendrás como yo, duras, llenas de marcas.

-Pronto, antes de darte cuenta...

- ¿Ves este dedo?

—Pues no lo puedo mover, me lo machaqué y así se quedó, tieso para siempre...

-Arreglando el carro.

-Fíjate, a uno se le muere un dedo, y no pasa nada.

- Te acostumbras.

—Las manos son lo primero en envejecer...

-Ya lo verás.

- A tu edad yo todavía estaba con mi familia. Éramos cinco hermanos y una hermana... Sí señor, toda una mujer mi madre. Tenía las caderas anchas y el vientre generoso, fértil, preparado para dejarse sembrar.

— ¿Y tu familia? Me extraña que no estés con ellos, pero bueno, eso no es asunto mío, ¿verdad?

—Era sólo por hablar. 
-El tiempo pasa muy lento si no se le distrae con algo, hay que emborracharlo para que vaya dando tumbos; ¿te lo imaginas?, el tiempo de un lado para otro, tropezando y levantándose...

-Así debía ser siempre...

- Aunque yo normalmente no hablo con nadie.

-Yo hago mi camino solo.

—Es como mejor se está.

-Solo.

-Ya te darás cuenta.

- Las compañías lo entorpecen a uno, lo vuelven lento y descuidado.

-Yo necesito que mis piernas estén libres, sin enredarse con los pasos de nadie...

- Solo. Como mejor se está.

-Pero, fíjate que esta tarde, sin saber por qué, me encuentro contigo y me has llamado la atención, al verte así como ibas, perdido, con tu saco a cuestas. perdido.

- iMira que eres testarudo! Si yo te digo que ibas perdido, es que ibas

-Eso se nota. Conmigo no tienes que hacerte el fuerte...

- Si casi podrías ser mi hijo.

-Yo también iba así al principio.

- Con un saco.

- Y toda mi tierra dentro.

—Nada más.

- Igualito que tú...

- Hasta que conseguí el carro. Me lo gané haciendo lo único que yo sé hacer de verdad bien: pintar retratos.

- ¿No te lo crees?

-Pues porque ya está cayendo la noche y hay que prepararse para dormir, que si no te lo iba a demostrar... 
—Trece retratos a cambio de este carro. No está mal...

-Toda una familia, uno por uno: a la niña pequeña, con su sonrisita llena de agujeros; al padre, mirando al frente, como una montaña puesta en el medio; a la abuela, arrugada como un sapo; al hijo mayor, con su mujer, que tenía mirada de gorrión; a la madre, pequeñita y panzuda; al... hermano del padre, que no paraba nunca de moverse, como si tuviera piojos por dentro...

— ¿A quién más?

—No sé, ya he perdido la cuenta...

-Trece, casi un pueblo, ¿verdad?; iban todos juntos, con cuatro carros.

-Me dieron éste, el que estaba más viejo, pero yo le hice sus arreglos, y lo dejé así como lo ves; no he querido ponerle adornitos, eso no va conmigo...

-Ni nombre tampoco.

-Porque hay gentes que hacen eso, que les ponen nombre a las cosas.

- Como si así no fueran a perderlas nunca...

—Yo ya no, nada de nombres; antes alguna vez, por puro juego, por juventud, pero luego dejé de hacerlo...

-Ahora las cosas son sólo eso, cosas, y esto pues es «el carro», sin más ni más, el carro con el que llevo andando desde hace... seis años...

-Al principio, no, al principio lo llevaba todo a cuestas, como tú...

—Aunque yo tenía mejores espaldas...

—Tú estás un poco flaco.

(Ha terminado de poner su tierra sobre los sacos, la ha aplastado un poquito con las manos. Después se acerca al carro, vuelve con una cantimplora, le ofrece con un gesto al chico y bebe.)

— ¿Sabes qué se necesita para hacer un buen retrato?

-Pues te lo voy a decir: lo importante es mirar bien.

- Yo miro la cara de alguien y ya le saco parecido con algo, con un animal o con un objeto. Hay gente que tiene expresión de agua, otros de aire, otros de piedra...; pero hay que saber mirar. 
—Tú, por ejemplo...

-Tú tienes cara de... ¡un becerrillo!, eso mismo. Que sí, que te lo digo yo... Fíjate que parece que vas a echar a balar en cualquier momento...

-No te molestes, hombre... Tener cara de becerro a tu edad no es ofensivo, es normal. ¿O quieres ya tener cara de toro?

- Todavía te falta...

— ¡Mira!, te lo voy a demostrar, aún nos quedan unos minutos de sol...

(Vuelve hacia el carro y de un zurrón saca papel

y un lápiz muy gastado.)

- Hace mucho que no dibujo y ya tenía ganas, ya... Además, no pareces muy nervioso y eso está bien: lo peor es dibujar a alguien que está todo el rato moviéndose.

(Se queda quieto de pronto, a la expectativa. En susurros.)

— ¿Has oído eso?

—No, no era el río...

(Deja los materiales de dibujo en el suelo y mira alrededor con mucha atención. Grita hacia el vacío.)

— ¿Hay alguien ahí?

— ¿Eh? ¿Hay alguien?

(Saca un garrote del carro.)

- ¡El que sea, que salga si no quiere que vaya a buscarlo!

(Al muchacho.) — ¡Shittt! No te levantes...

(Se mueve despacio, escuchando. Le habla al muchacho en susurros.)

— ¿Que no era el río, joder!

-Eran pasos...

—Pasos de hombre...

(Gritando, hacia el vacío.)

— ¡He dicho que salgas!... 
- Hijo de puta cobarde...

(Deja de buscar.)

- Seguro que se ha largado corriendo con el rabo entre las piernas.

-Parecen muy valientes, pero a la hora de la verdad...

— ¡Te estoy diciendo que sí!

-Al menos había uno.

—Lo he oído... Con eso hay bastante.

- Siempre intentan pillarte desprevenido, los muy cabrones.

—Ésta es la peor hora, muchacho, la peor... Porque todavía no ha desaparecido la luz del todo.

—Y a ellos también les da miedo la oscuridad.

- $\mathrm{Si}$ los conoceré yo...

—Llevo veintidós años así, muchacho, de un lado para otro.

- Veintidós años.

- Casi una vida...

-Y me he encontrado con muchos de esos.

-Esperándote en cualquier parte...

-Por si vuelve, vamos a dejar esto a mano, que nunca se sabe.

(Recoge el lápiz y el papel. Se sienta sobre la tierra, con el garrote cerca. Comienza a dibujar.)

—A ver, ponte de perfil... No, no; mejor como estabas antes...

(Va haciendo trazos rápidos en el papel mientras habla, a ratos se detiene, mira al muchacho y luego retoma la tarea. Aspira fuerte.)

— ¡Cuánto me gusta este olor! ¿No lo notas?

-Manzanilla...

-De ésa que se cría en el borde de los caminos.

- La recojo, la desmenuzo y la mezclo con mi tierra. 
-Así sé que estoy en mi sitio.

- Todo el mundo lo hace, cada uno a su manera, según su carácter; los que añoran el mar, le revuelven caracolas; otros la pintan de colores, roja, verde, azul, dependiendo de cuál sea su preferido...

-Hay que hacer esas cosas, ¿sabes?

-Tú las harás también, estoy seguro, algún día; pero primero debes descubrir qué es para ti lo necesario.

- Lo que te hace sentir bien.

_ ¡Para mí, la manzanilla! ¿Te hace gracia?

-Pues conocí a un hombre que les arrancaba los pelos a las mujeres... Sí, lo que oyes, a las mujeres, a todas, a las desconocidas también, y de todas partes, cuantos más mejor, y luego los metía entre su tierra... ¡Si vieras la de veces que aparecía hecho un guiñapo, sangrando por todas partes o lleno de moratones! ¡Los maridos, claro, pero también ellas, que le saltaban a la cara con las uñas por delante!

—El pobre decía que le daba igual, que no le quedaba más remedio.

- ¡Creería que así le iba a nacer una muchacha sólo para él!

-Eso creería, digo yo...

-Porque cualquier día de estos, le meten una paliza que lo matan, y se acabó todo.

—A lo mejor está muerto ya.

—Quién sabe...

—Bueno, ya sí que no puedo seguir. Me falta luz.

(Se levanta y se aparta a una esquina a mear. Habla desde allí.)

-Puedes mirarlo si quieres. Es sólo un boceto, pero tiene algo de tu expresión.

-Aunque tú seguramente no te vas a reconocer.

-Uno siempre tiene otra imagen de sí mismo...

(Vuelve a su sitio. Breve pausa. Coge un puñado de tierra y lo va dejando caer poco a poco. Repite el gesto algunas veces más.) 
—Lo importante es mimarla, ¿sabes?

-Dedicarle su tiempo cada día, no limitarse a llevarla y traerla...

-Hay que limpiarla, acicalarla, hacerle regalos, como si fuera una mujer.

— Si no se hacen esas cosas uno puede acabar odiándola.

-Ya lo verás, llegará un día en que ese saco pese mucho, cien veces más que tú.

—Siempre llegan esos días.

-Más tarde o más temprano...

- Cuando la carga es tan grande que cuesta caminar.

-Entonces sentirás la tentación de dejarla por ahí, tirada, como si no sirviera ya, y seguir adelante, ligero, con las espaldas descansadas....

-Dentro de ocho o diez años...

-Ya lo verás.

-Un día te das cuenta de que ya no tienes ni mujer, ni hijos, ni nadie que te ayude y cada vez cuesta más.

-Por eso tuve que buscarme el carro.

-Para poder seguir...

(Saca tabaco de liar y papel y se va preparando un cigarro.)

-A veces...

-A veces me da por imaginar, no sé..., que..., que las cosas cambian, que todo esto cambia.

- Me tiro un buen rato pensando, y es como si soñara, pero despierto.

- ¿A ti no te pasa nunca?

-Es como... ¡como dibujar con la cabeza!... Así es... Con mucho cuidado, sin olvidar ningún detalle, poniendo tanta atención que parece que el dibujo es de verdad, que está ahí delante...

-Entonces alargo la mano para tocarlo... y me doy cuenta de que sigo en este mundo y que todo está como siempre...

—(Respondiendo.) No, nunca, ¿quién iba a prestarme atención? 
-Aquí cada uno va a lo suyo, muchacho...

—Además esas cosas es mejor quedárselas dentro, bien escondidas.

—No me fío de la gente.

-Eso me ha enseñado el caminar tanto, que no hay que esperar nada de nadie. Cada uno a lo suyo, con su silencio a cuestas.

-Y si esta noche estoy contigo, pues es..., no sé por qué es, joder..., iporque me ha dado la gana...! Pero yo no soy tu maestro, ni tu padre, ¿te enteras?

—Ni siquiera sé por qué me he acercado a ti.

-Ya te he dicho que yo voy siempre solo.

-Así es como me gusta estar...

-Yo no puedo enseñarle nada a nadie.

(Ha terminado de liar el cigarro. Le ofrece al chico con un gesto. Después se lo enciende y empieza a fumar.) fiar?...

—Además, ¿por qué te lo iba a contar a ti, eh? ¿Cómo sé que eres de

-A ver, acércate.

— ¡Acércate!, hombre, ¿no me digas que te doy miedo?

—Déjame que te mire bien...

—-(Sonriendo.) Sí que tienes cara de becerrillo, sí...

—De becerrillo asustado...

-(Decidiéndose.) Escúchame, ¿tú serías capaz de prometerme que lo vas a guardar bien?

- Lo que te cuente: eso que yo dibujo, con mi cabeza...

—No, no es sólo que lo mantengas en secreto, es otra cosa...

-Quiero que me prometas que lo vas a conservar en tu memoria, muy hondo, para siempre, ¿comprendes?, y que dentro de muchas noches, cuando ya no te acuerdes de mi voz, ni de que tengo un dedo inútil y que pintaba retratos, entonces, dentro de muchas noches, quiero que sigas recordando lo que te diga ahora... 
— ¿Lo prometes?

—Ya sé que esas cosas no se pueden pedir..., pero dime que sí, de todos modos, aunque no estés seguro.

— ¡Eso es, muy bien! Te vas a acordar, yo lo sé, claro que sí. bujo un sitio.

A veces dibujo, pero de verdad, ¿sabes?, hasta llegar a verlo..., di-

-Un sitio normal, ni muy grande, ni muy pequeño, donde puedan caber un hombre y una mujer...

—Un sitio como éste, con un río cerca y con las montañas allí, al fondo.

-Entonces imagino que llego allí, tiendo mi tierra y no tengo que recogerla al día siguiente ni al otro.

-i¿Entiendes!?

-Me quedo todo el tiempo que yo quiera.

— ¿Sabes cuánto es lo máximo que he durado en un mismo lugar?

-Doce días...

-Un dos tres ¡cuatro, cinco, seis, siete, ocho, nueve, diez, once, doce.

- ¿Ves? son muy pocos; no da tiempo a casi nada en doce días, y sin embargo ya había empezado a reconocer ese lugar: aprendí cómo estaban colocados los árboles, sabía dónde se encontraba cada hormiguero, hasta le puse nombre a algunas de las rocas, las que tenían formas más extrañas:

— «La Perezosa», una muy ancha que estaba como tumbada y parecía que iba a bostezar en cualquier momento,

— La Cabeza de Cuervo»,

— «La...»

-No sé... Por entonces yo era joven, todavía...

— «La Perezosa»,

— «La Cabeza de Cuervo»...

-Sólo me acuerdo de esas dos...

—Pero había más, ocho o nueve por lo menos... Y busqué los nombres apropiados, uno para cada una. 
—En doce días no da tiempo a más...

-Hubo que irse, claro, siempre hay que irse...

—Pero si hubiera podido, me habría quedado en ese lugar... o en otro cualquiera.

— ¿Imaginas?

-Poder plantar algo y que crezca...

—Tomates, acelgas, patatas...

— ¡Naranjas!, ¡naranjas también!

-Poner una semilla y esperar a que germine, que nazcan raíces y hojas y ramas

-Y nuevas semillas que volver a plantar...

-A lo mejor llega un tiempo en que es posible dejar de moverse, ¿no crees?

-Y entonces habrá que aprender cuándo es la mejor época para sembrar trigo, porque el trigo es muy necesario, y cada uno cultivará su parte.

— ¿Eres capaz de verlo?

— iCada uno su parte!

—Un horizonte amarillo en los ojos.

—¿Quién dice que no? ¿Eh?

- ¿Quién dice que no?

-Podríamos hacerlo...

—_Alguien nos lo prohíbe? ¿Tú lo sabes?

— ¿Tú sabes por qué seguimos así, andando, de un lado para otro?

— ¿¿Tú sabes por qué lo hacemos?!

-No, claro que no lo sabes... Ni siquiera te lo has preguntado... Eso nadie se lo pregunta al principio. Lo haces, porque sí, porque es lo que hay que hacer, lo que se ha hecho desde siempre...

-Eso nos han dicho, que se ha hecho desde siempre... 
-Pero, ¿por qué no podemos parar?

— ¿Quién no nos deja parar?

- ¿Quién?

—¿Quién?

-(Comienza a reírse.) Debes de pensar que estoy loco...

— ¡El loco del dedo inútil!

— ¡El loco de los dibujos!

—(Deja de reír.) El que se cree sus propios sueños...

- Sí, debes pensarlo. Yo también lo pensaría si fuera tú y me encontrara conmigo...

-Pero da igual. Da igual...

-Nunca le había contado esto a nadie. Y sé que tú lo vas a guardar.

-Me lo has prometido.

- Aunque ni siquiera lo entiendas, aunque seas tan joven y todavía no sepas cuánto llega a pesar esta tierra...

—Esta tierra donde nunca nace nada...

(Desata la flauta que lleva atada a la cintura. La limpia con mucho mimo. Toca durante un rato, una música sencilla, con la que parece ir alejando poco a poco los pensamientos anteriores.)

— ¿La conoces? Es una canción antigua. Seguro que te suena...

(Vuelve a tocarla.)

-A lo mejor escuchaste a tu madre cantarla alguna vez.

-A mi mujer le gustaba mucho.

- Se pasaba todo el día tarareándola...

(Canturrea. Se queda quieto un momento, en silencio.)

- Ha empezado a refrescar...

(Deja la flauta y va hacia su carro. Saca una manta vieja con la que se envuelve.) 
— ¿Tienes algo para abrigarte? ¡Hombre, qué sorpresa! Una piel muy buena... De las que se hacían antes...

-Yo tuve una parecida, un poco más oscura tal vez.

- Seguro que te la regaló tu padre.

-Te gusta quedarte callado, ¿verdad? Yo tampoco hablo mucho, normalmente...

-Bueno, sí, hablo conmigo, pero eso no cuenta...

- Sobre todo si hace viento, entonces parece que alguien te responde.

-Alguien desde muy lejos...

-Una buena piel, sí señor, con esa no vas a pasar frío en todo el invierno. Sólo debes tener cuidado de que no te la vayan a quitar... Porque esos hijos de puta son capaces de cualquier cosa y todavía eres muy joven...

-Podrían pillarte desprevenido.

-A mí una vez me robaron una vez, sólo una vez, algo muy importante...

-Pero aprendí la lección. Desde entonces, el que quiera quedarse con algo mío, tiene que matarme primero. Y matarme a mí, no es fácil...

—Nada fácil.

— ¿Sabes por qué? Porque me he acostumbrado a escuchar.

—Sí, a escuchar...

- Cuando parece que no hay nadie, cuando todo está en calma, sshhhiisshhh, yo sigo escuchando...

—Nunca bajo la guardia.

-Mientras estoy dormido y todo mi cuerpo parece como muerto, mis orejas, no; ellas están despiertas siempre... Y en cuanto reconocen los pasos de alguien, ya estoy de pie con mi garrote en la mano.

—Es importante no dudar...

-Asestar un golpe, rápido, y que el brazo avance solo, sin pedir permiso a la cabeza...

- Si se piensa, aunque sea durante un parpadeo, le das al otro la oportunidad de golpear antes... 
-Es importante no dudar... Eso lo aprendí muy bien...

- Lanzarte sobre su cuerpo con el arma bien agarrada y derrumbarle como si sólo fuese un saco de piedras...

-Porque esos no son hombres, muchacho, que te quede muy claro.

- Los hombres saben respetar lo que no es suyo.

-Yo nunca he buscado la tierra de nadie. Cada cual tiene la suya; la ha heredado de sus padres, y antes perteneció a sus abuelos, y así hacia atrás...

- Hacia muy atrás.

- Cada quien la suya. Eso es una ley...

-A veces, cuando estoy tumbado, me parece que escucho las voces de mi familia, ¿comprendes?, llegan lejanas y como hechas de humo, pero están ahí...

—Y están las huellas de sus cuerpos...

- Tal vez mi madre ponía aquí los pies para que mi padre se los calentara; aquí solía jugar su primera hija, la que murió antes de que yo naciera; aquí mi bisabuelo se hincaba de rodillas para quitar las hormigas...

—Esto es lo que me queda de ellos...

—Y están todos, todos, los que vivieron cincuenta años y los que ni siquiera duraron un día.

—No debemos olvidarlo nunca...

—Por eso a mí no me ha importado matar por defenderla.

- Sin dudar, levanto mi arma y la dejo caer, de un mazazo, sobre el cuello de alguien que no merece llamarse hombre, que es menos que un perro o una rata.

—No recuerdo nada de ellos.

-Podrían haber sido jóvenes o viejos, altos o bajos...

— Sólo sus ojos, eso sí, eso no se me olvida, sus ojos justo antes de morir.

— ¿Has visto a alguien en ese momento?

—La mirada les cambia, como si pudieran ver a través de las cosas... 
—Ellos miraban de esa forma, a través de mí, y yo seguía golpeándoles, una y otra vez, una y otra, y otra, y otra, hasta que ya no les quedaba ninguna cara con la que mirarme.

- Siempre hago lo mismo, les dejo ahí, a la intemperie, y me siento a esperar, sabiendo que los buitres no tardarán.

-Querría devolverles la vida en ese momento, para que se vieran así, con las tripas al aire, sin brazos ya, ni cabeza, ni piernas.

- Los picos entran en la carne y la arrancan, ¡chas!, de un tajo, haciendo un ruido seco.

— Nunca pensé que la carne pudiera sonar de ese modo...

—Era lo que se merecían.

-Que uno intente aumentar su tierra, me parece bien... Pero sin robarla, muchacho, sin robarla. Hay quien tiene demasiada y te la cambia por otra cosa. Hay quien te la deja como herencia, quien te regala un puñadito en agradecimiento por algo...

— ¿Nadie te ha enseñado esas cosas?

- ¿Te crees que mi padre me dio todo esto? No, chico, no, éramos cuatro hermanos, y no había tanto para repartir...

-Ni un saco lleno tenía entonces; el resto me lo he ido ganando yo, con mi trabajo.

—Siempre con trabajo...

-Una vez me crucé con un hombre, no muy viejo, parecía menor que yo...

- Le sorprendió la muerte mientras dormía. O eso pensé, por la forma en que lo encontré tumbado.

—Allí estaba, con toda su tierra, ¿comprendes?... y había mucha...

—No sabía qué hacer..

- Hubiera podido recogerla y haberla juntado con la mía... A nadie le hubiera perjudicado, porque el hombre estaba ya tieso y su carne tenía ese color azul de quien lleva varias horas muerto... Yo le habría dado una utilidad... 
-Por entonces mi mujer estaba conmigo, y queríamos tener hijos, ¿sabes? Con esa tierra y la mía, les hubiera podido dejar una herencia.

-Una buena herencia...

-Pero ella no quiso.

—Decía que si nos la llevábamos, ese hombre no iba a descansar en paz, ni nosotros tampoco.

-Tenía esa forma de pensar...

-(Sonriendo.) Y, cuando tomaba una decisión, bueno..., no merecía la pena discutir... Sólo llevábamos dos años juntos, pero ya la conocía bien, y sabía que cuando ponía esa voz...

—De modo que lo tiré al río, con sus dos sacos atados a las piernas.

- Lo vimos hundirse, inmediatamente, y nos quedamos todavía un rato, mirando el agua, esperando no sé qué... bien.

- Seguramente ella llevaba razón, hacer otra cosa no hubiera estado

- Siempre llevaba razón, aunque yo a veces tardaba en darme cuenta.

-Pero no quiero hablar de ella...

— ¿Acaso me meto yo en tu silencio?

-No has contestado a ninguna de mis preguntas, y yo no he insistido, ¿verdad?

—i Verdad?!

—Pues tú deberías hacer lo mismo. Respetarme...

—Ella está aquí (Se señala la cabeza.), y aquí (Se señala el corazón.), y aquí (Mete las manos en la tierra.)...

-Ella está en todas partes: en mi música, en mis sueños, en mis retratos... En todas partes... Para siempre, ¿entiendes?

—Y no voy a dejar que nadie me la vuelva a quitar...

¡NNadie!...

(Se levanta, exaltado, con su garrote en la mano.) 
— ¿Los oyes? ¡Ya están aquí otra vez!

—Nunca se dan por vencidos...

— ¡Salid!, ¡salid!, que os estoy esperando...

(Da vueltas a ciegas, dándole golpes al aire.)

— ¡Venga!, ¡ya no me encontráis desarmado nunca más!

— ¿Me oís?

— ¡Ahora no me la podéis quitar!

— ¡Ahora voy a saber defenderla!

— ¡Ahora sí!

— iSalid, cabrones!

—¿Dónde os habéis escondido?

- ¡Salid!

(Tropieza y cae al suelo.)

- ¡No! No te acerques.

-Yo me levanto solo. Estoy bien...

— Te he dicho que estoy bien!

(Se levanta.)

— ¿Por qué me miras así, eh?

— ¿Qué estás pensando?

— ¿Te doy pena?

—Eso es, te doy lástima...

—Ya sé lo que piensas de mí: «Pobre viejo loco, que no vale para nada, que casi no se sostiene en pie.»

-Lo escucho, aunque no lo digas:

— «Seguramente está enfermo...

— ¿Cuánto le quedará de vida?

- ¿Un mes? 
— ¿Un año?»...

-Pues no te hagas ilusiones. Todavía puedo pelear contigo y ganarte, ¿te enteras? ¿O qué te habías creído? ¿Que me ibas a pillar descuidado?

(Se acerca al muchacho lentamente, con el garrote en la mano.)

-No soy tan idiota...

—Ése era el plan, ¿verdad?, esperar hasta que estuviera dormido para lanzarte sobre mí y luego llevarte todo esto... Por eso te quedabas ahí, tan callado...

-Tan atento.

—A saber a quién le habrás robado esa tierra...

— ¡Pero a mí no me has engañado! Yo os conozco bien...

(Amenazándole con el garrote.)

— $i$ Venga, sal corriendo! Te voy a dar esa oportunidad...

—iVamos!

—A qué esperas! ¡Sal corriendo o te aplasto la cabeza!

— ¿No me crees?

(Pega un golpe contra el suelo.)

—ES que quieres que te mate, eh? ¿Eso quieres?

-Podría hacerlo...

—Antes de que te des cuenta, ¡un golpe ahí, por detrás del cuello!

—iY ya está!

(Cada vez más derrotado. Va dejando caer el garrote.)

— ¡Sólo serías uno más! ¡Sólo eso!

—QQué más da uno más!

—Lárgate de una vez...

—No soporto que te quedes ahí quieto, mirándome de esa manera...

-Me miras, me miras, me miras... 
—QQué quieres de mí?

—Tú no tienes ni idea, ¡ni idea!

-Yo intenté defenderla, ¿te enteras?...

-Claro que lo intenté... Pero entonces no sabía...

—Entonces... era muy joven, ¿entiendes?...

— ¡No me quedó otro remedio! Si no me hubiera ido nos hubieran matado a los dos...

—Eran muchos, diez o doce, y... iban armados...

— ¿Qué habrías hecho tú, eh?

— ¿Qué habría hecho cualquiera?

-Mientras corría sólo volví el rostro una vez, sólo una.

-Ya la habían tirado al suelo.

— Vi sus piernas, sus piernas blanquísimas, abiertas de par en par, sin moverse...

—Uno le sujetaba las brazos y otro estaba encima de ella.

—Los demás esperaban a que les llegara su turno...

- Corrí más rápido, hacia delante, hacia delante, no sé durante cuánto tiempo.

- Todavía me despierto escuchando sus gritos llamándome, cada vez desde más lejos.

-A veces pienso... pienso que a lo mejor ella... que a lo mejor la soltaron y sigue viva...

— ¿Qué le voy a decir si un día me la encuentro? decir...

-Yo sé que la mataron, siempre las mataban, lo sé... pero, qué le podría

— ¿Te das cuenta?

—Deberías marcharte, ahora que puedes, y dejarme solo...

¡Solo!

—_A qué esperas? No soy buena compañía... 
-Por eso no me gusta la gente, porque todos son iguales que yo...

-A ti también te pasará: te acostumbras a sobrevivir, cueste lo que cueste, y ya no puedes hacer otra cosa.

- Siempre es así.

-O a lo mejor no, quién sabe...

—Tú todavía tienes tiempo...

(Saca lo necesario para liar otro cigarro.)

— ¿Seguro que no quieres uno?

-A mí me sirven, sobre todo a esta hora, cuando ya no hay mucho que hacer...

-Fumar, tocar la flauta, contar estrellas: a eso me dedico yo cuando la luz se ha ido del todo...

-Y dejar que pase el tiempo...

-Una, dos, tres, cuatro...

-Esta noche hay pocas...

-Cinco, seis, siete...

-Ocho, nueve, diez, once, doce...

— ¿Sigues ahí?

-Ya casi no te veo...

- Si quieres dormirte, dímelo y me callo...

-A mí me gusta trasnochar...

—Desde niño, puedo pasarme mucho tiempo mirando el cielo...

— ¿Sabes lo que dicen?

-Que cuando la luna está así, como ahora, es cuando el mundo crece.

-Al par que ella, todas las partes del hombre, las uñas, los pelos, los huesos, todo, pero también los animales, y los árboles y la hierba...

-Todo...

—Sí, muchacho, el trigo también, seguramente..., el trigo, en alguna parte... 

sueños..

—No te olvides de prestarle atención al sonido del río, que te mejorará los

—Mañana... yo querría darme un baño, y tú también, ¿verdad?

-No hay mejor forma de empezar el día

—Y después... da igual, ya decidiremos...

- Hacia el sur casi nunca hace viento...

-Y los días son más largos...

- Seguro que te gusta...

—Quién sabe, a lo mejor allí puedo terminar tu retrato...

-Ya veremos...

-Ahora descansa, muchacho...

—Que queda mucho camino...

(Saca su flauta. Empieza a toca. Poco a poco el sonido va descendiendo).

FIN

Diciembre de 2002 